\title{
'Rings of fire': the hoops to jump through for Community Sexual and Reproductive Healthcare equivalence
}

\author{
Jane Dickson
}

Acting Consultant in Sexual and Reproductive Health, Oxleas NHS Foundation Trust, Woolwich, London, UK

\section{Correspondence to} Dr Jane Dickson, Oxleas NHS Foundation Trust, 20 Market Street, Woolwich, London SE18 6QR, UK : jane.dickson@nhs.net

Received 23 June 2013 Revised 22 July 2013 Accepted 23 July 2013 Published Online First 23 August 2013
To cite: Dickson J. J Fam Plann Reprod Health Care 2014;40:11-13.

\section{BACKGROUND}

I have recently been successful in my application for a Certificate of Eligibility for Specialist Registration (CESR) in Community Sexual and Reproductive Healthcare (CSRH). Other than the generic information available, there were few resources to guide me through the application. Consequently, I made many mistakes along the way. I have written this article to help others navigate the process and hopefully help prevent them from making the same mistakes that I did. The process is not easy but it is entirely possible to succeed with perseverance.

\section{INTRODUCTION}

After 8 years as a principal in general practice, I realised that the community family planning clinics I did additionally were the only aspect of my work that I enjoyed. I left general practice to become the clinical lead of the Greenwich Sexual and Reproductive Health (SRH) Service in January 2005. I have worked in a 'consultant' position since this time and the creation of the new specialty of CSRH allowed me to apply to the General Medical Council (GMC) for entry onto the specialist register by virtue of equivalence [i.e. the CESR].

\section{WHY APPLY?}

Doctors in my position are usually recognised as 'specialists' locally, yet recognition by the GMC is a far more 'transferable' asset. Lead SRH doctors who are not consultants have often undertaken significant training in the specialty and already have many of the competencies required to prove equivalence. The new specialty of CSRH is dependent upon others in my position undertaking the CESR process to increase the number of consultants. This will develop the opportunity for career progression in $\mathrm{CSRH}$ and will guarantee that patients are seen in services appropriately led with excellent governance and consistency. It is also an enormous boost to your self-esteem when successful!

\section{HOW TO BEGIN}

In order to demonstrate equivalence, it is necessary to prove that the competencies of a 'Day One' consultant are met. There are two areas of guidance that one must be familiar with before starting:

1 The trainee portfolio and curriculum for the 6-year run through training programme in $\mathrm{CSRH}^{1}$

2 The GMC Specialty Specific Guidance for application for a CESR in CSRH. ${ }^{2}$

These outline the competencies that need to be met and the 'evidence' that is required to prove equivalence. Six months must have been undertaken in a relevant training post (e.g. Obstetrics and Gynaecology).

The Membership examination of the Faculty of Sexual \& Reproductive Healthcare (FSRH) is the formal assessment of knowledge to support a CESR application, but the GMC does outline an alternative for those who have not passed this examination. The GMC states that "if you cannot demonstrate success in this examination then other supporting evidence of your knowledge must be very strong indeed" and suggests that evidence should include details of other specialist examinations passed and lists evidence (e. g. national and international presentations), which may be used to demonstrate equivalence to examination success. 
Box 1 Curriculum modules for the specialty train-

ing in Community Sexual and Reproductive Healthcare

$\begin{array}{ll}\text { Module 1 } & \text { Basic clinical skills } \\ \text { Module 2 } & \text { Contraception } \\ \text { Module 3 } & \text { Unplanned pregnancy and abortion care } \\ \text { Module 4 } & \begin{array}{l}\text { Gynaecology } \\ \text { Specialist gynaecology: fertility, oncology and } \\ \text { Module 5 }\end{array} \\ \text { urogynaecology } \\ \text { Module 6 } & \text { Pregnancy } \\ \text { Module 7 } & \text { Menopause and premenstrual syndrome } \\ \text { Module 8 } & \text { Genitourinary medicine } \\ \text { Module 9 } & \text { Public health } \\ \text { Module 10 } & \text { Teaching, appraisal and assessment } \\ \text { Module 11 } & \text { Ethics and legal issues } \\ \text { Module 12 } & \text { Leadership, management and governance } \\ \text { Module 13 } & \text { Information technology, audit and research } \\ \text { Module 14 } & \text { Sexual assault } \\ \text { Module 15 } & \text { Sexual problems }\end{array}$

\section{THE CURRICULUM}

The curriculum has 15 modules (Box 1). Several modules are easily demonstrable if the applicant is working routinely in SRH. However, some may only be experienced in certain areas of practice (e.g. abortion care).

Download all the training documentation ${ }^{3}{ }^{4}$ and review which competencies can be proved and identify which will require additional experience. Every competency must be achieved for an application to succeed. There were many areas where I had plenty of evidence (e.g. contraception, sexual health and 'management') but I also identified weaknesses (e.g. surgical gynaecology, abortion care and sexual assault) and recognised that I would require further experience.

\section{HOW TO PROGRESS}

First, identify supportive colleagues to sign the logbook testifying to your competencies. This may require a direct review or observation of clinical practice. Where experience is insufficient, identify possible trainers and begin to approach them. Everyone that I approached was supportive but not always able to help. Sometimes it may be difficult to find a training placement and long-distance travel may be necessary.

Every placement requires an honorary contract and the time taken for this process is variable. It is best to evidence any new training by undertaking formal workplace-based assessments. It may also be necessary to undertake some assessments to provide evidence that past competencies are still held (e.g. if careergrade training was completed several years previously). There may be some areas where significant work will need to be undertaken (e.g. a public health project) so be realistic about the time that the process may take.

\section{EVIDENCE TO BE SUBMITTED}

Evidence falls into four categories and the application should be compiled accordingly.

Domain 1 - Knowledge, skills and performance (75\%) (i.e. the curriculum)

Domain 2 - Safety and quality (20\%)

Domain 3 - Communication, partnership and teamwork

Domain 4 - Maintaining trust.

Domains 3 and 4 together should only comprise $5 \%$ of the evidence and are very straightforward if you have led a service.

Certain evidence also appears to be particularly important:

1. Evidence of appraisals for the last 5 years

2. A $360^{\circ}$ feedback

3. A patient survey

4. A completed audit cycle (including re-audit).

\section{LOGBOOKS}

Clinical logbooks can be used to evidence procedures that are undertaken and can evidence additional training. Evidence of any training must be validated.

\section{VALIDATION}

The GMC will not accept original copies of documentation so evidence should be copied. Copies of training evidence should be stamped with the badge of the training institution and then signed by your supervisor. The first page of this documentation should also have your supervisor's name and position printed upon it. Evidence corresponding to work undertaken in your own institution can be validated internally (e.g. by your Medical Director).

\section{TRIANGULATION}

Triangulation is the process by which pieces of evidence support each other to build up a profile of your competency. As an example, for menopause care one might include:

- Menopause conference attendance

- Anonymised menopause clinic list

- Your own hormone replacement therapy formulary

- Referral letter to you from a general practitioner (GP)

- GP letter including a treatment plan.

The evidence is placed in different areas of your portfolio but when triangulated will help the assessors evaluate your skills and breadth of practice.

\section{CHOOSING YOUR REFEREES}

Six referees are needed to support your application. A structured reference is required and this is virtually impossible for the referee to write if they do not have personal knowledge of your clinical work. Choose referees who have seen you work clinically, and if this is 
not possible from your SRH work, choose people who have observed you recently (e.g. those who you have supervised you during your 'additional skills' training). Ideally, your first referee should be your Medical Director.

\section{SUBMITTING YOUR EVIDENCE}

Register with the GMC website so that the 'My GMC' facility can be used. In 'My Registrations', register to undertake CESR, and access the 'Evidence Submission' template. You have a 6-month deadline between beginning the process and submitting your evidence. There is a formulaic table, and in each section specify what evidence is being submitted. For the final evidence submission I surrounded myself with evidence and stepwise completed what I was submitting against which criterion. Evidence should only be submitted in one section, and if you wish to re-reference, this should be indicated on the table (e.g. 'See feedback from lecture $\mathrm{X}$ in section Y').

When completed, pay the application fee to the GMC and submit all the evidence as a bundle (which should not exceed the capacity of an A4 box file) with a copy of 'The Evidence to be Submitted' summary. The GMC will e-mail confirmation of receipt and will allocate an Equivalence Assessor, who is the person with whom you can communicate for advice and information on the progress of your submission.

The GMC will contact your referees and your assessor evaluates your evidence. Anything not appropriately validated or evidenced will be returned to you for further details. When satisfied that your application is as robust as possible, your advisor will submit it to the FSRH Equivalence Committee for assessment. The evidence is reviewed and a recommendation made to the GMC as to whether or not the criteria for CESR have been met. If unsuccessful, specific feedback must be given explaining exactly why the submission has failed and what additional evidence is required for the application to succeed. Provided the additional evidence is submitted as outlined, the application should then be successful. Resubmission to the GMC requires further payment.

\section{...AND FINALLY}

After two and a half years of planning, travelling and training, I succeeded. The process is exhausting but there is nothing quite as positive as the GMC confirming that you are 'Valid'. If I can achieve this, so can any other 'jobbing' lead doctor in SRH. I am very happy to provide advice, support and encouragement to interested individuals if they contact me.

Acknowledgements There are so many people who have helped me and this has affirmed my faith that we are incredibly generous and kind as a specialty. I especially thank Lesley Bacon for being my mentor and closest supporter at the blackest moments; Jane Burch, Bernadette Butler, John Carr, Alyson Elliman, Charlie Fleming, Russell MacDonald, Samuel Marcus, Louise Massey, Kate McCarthy, Sue Mitchell and all at Greenwich Public Health for helping me to achieve my competencies; Kate Guthrie who pulled me through the final furlong; and the three people who helped me to cope (and who coped with me!), my husband, Aisling Baird and Fiona Dickson.

Competing interests None.

Provenance and peer review Not commissioned; externally peer reviewed.

\section{REFERENCES}

1 Faculty of Sexual \& Reproductive Healthcare. Community Sexual and Reproductive Health Curriculum. November 2012. http://www.gmc-uk.org/CSRH_Curriculum_27_November_ 2012_FINAL.pdf_51473364.pdf [accessed 22 June 2013].

2 General Medical Council. Specialty Specific Guidance for Certificate of Eligibility for Specialist Registration. http://www. gmc-uk.org/SGPC_SSG_Community_Sexual_and_ Reproductive_Health_DC2291.pdf_48458087.pdf [accessed 22 June 2013].

3 Faculty of Sexual \& Reproductive Healthcare. Training Documentation. http://www.fsrh.org/pages/Training Documentation.asp [accessed 22 June 2013].

4 Faculty of Sexual \& Reproductive Healthcare. Community Sexual and Reproductive Health Curriculum. http://www.fsrh. org/pages/CSRH_Curriculum.asp [accessed 22 June 2013]. 